\title{
Parameters of Transformation of Space and Time in Human Being in the Light of Synergetic Theory ${ }^{1}$
}

\author{
Prof. Dr. Ph.D. Bidzina Savaneli \\ Professor-Researcher of the Tbilisi State University (Tbilisi, Georgia), \\ Member of International Scientific Board of Mediterranean Center of Social and Educational Research and \\ Editor in Chief of Mediterranean Journal of Social Sciences (Rome, Italy)
}

\section{Doi:10.5901/mjss.2014.v5n27p1746}

\section{Abstract}

This article is a pioneering scientific work at the intersection of natural, social and human sciences, which aim is to ensure sustainable peace and prevent global disorder on the planet through a critical review of second law of thermodynamics and the application of synergetic theory to the being of humanity and make contribution in creative transformation of the natural normative order in the social, national and international normative orders at the regional, national and international level under the aegis of the bill of rights. The proposed theory offers a new mechanism for overcoming existing disorders and preventing new disorders, in other words, it opening door for "to teaching of humankind - to be able to join the supernal order of orders" (Shota Rustaveli XII c.). The article is based on comparative analysis of studies of Kant, Hegel, Newton, Lobachevsky, Planck, Einstein, Heisenberg, and Georgian philosophical, sociological, anthropological, legal traditions. The author has a noble goal to provoke the colleagues from different disciplines in order to participate in the building of bridges between the natural, social and human sciences for properly "fitting" humanity in harmony with nature. The article serves as a fruitful source of new ideas for students, researchers and professionals working in the field of physics, biology, ecology, anthropology, sociology, law, or related fields.

Keywords: Eternity of Space, Temporality of Time, Relativity of Laws of Thermodynamics, Synergetic Everywhere, Order and Disorder, Human Rights.

\section{Introduction}

"Let us forget about running time; forget of controversy of judgments. Let us address to everlasting and take our place in there".

Chuan-Tsi

"In this spiritual world there is no distinction of time among past, present and future: they all merge into one sole moment of livingly tremble being... This moment of individual illumination includes in itself past and future, which stands on the place with all its contents but exists in perpetual movement."

Sudzuki

"If nobody asks me about time, I know what is; if I wanted to explain Who asking me - no, I do not know". Beatific Augustine, Confession."

Book 11, Chapter 14.

I introduce a short formula: "Space is not temporal, but time is temporal. In other words: Space is perpetual, but time is with brakes.

More broadly, I would like to underline the following. The space is immortal, perpetual, lawful and spirally moving material space which is beyond a time. All material parts of space are moving within it, but not - in time. In this sense,

\footnotetext{
1 This article is much planned version of Paragraph 3 and 4 of Chapter III of Vol. 1, and Chapter IV of Vol. 2 of Monograph: "Bidzina Savaneli, Global Order or Global Disorder, Academic Edition «Lambert», in English, Saarbrucken, Germany, January, 2014", which produced due to an analysis, theoretical generalization and critical comprehension of the work of scientific researches indicated in the end of article through the prism of studies of Leibniz, Kant, Hegel, Newton, Lobachevsky, Planck, Einstein, Broglie, Bohr, Lobovikov, Heisenberg, and in Legal Philosophy - Kelsen and Naneishvili related to suggested by me the dialectical and synergetic transformation in human being oriented on the harmonization of natural and humanitarian sciences based on the Universally Recognized Human Rights and Freedoms.
} 
time as nonmaterial phenomenon is immovable and not immovable, time substantially does not exist. Contrary to the time, space exists, i.e. it is immortal and thus absolute. Yet concrete bodies in space seem to be born, changing and dying in the time, but this process coincide with the mutual process of dying, changing and born of other bodies within space limits that is beyond the time. Man only combines time with the life of concrete body artificially separated by him from the other bodies.

Concrete bodies in space are the clots of interactional "things-in-itself". The space is entity of'things-in-itself', in which actually there is no place for time. 'Things-in-itself' have no boundaries because boundaries mean timely brokenness among 'things-in-itself', which excludes timeless interaction among them. All existing in space does not depend on our consciousness, thus emptiness is just a man's phantasy. Something likely A. Einstein wrote: "We know that difference between past, present and future is only firm illusion."

Therefore, time artificially measured, but space is naturally not measured.

Finiteness of time and infiniteness of space is revealed and proved by a lot of experiments in high energy physics where the main players are represented by particles moving at speed of light. Let us imagine any observer in laboratory. The observer is moving from time to time, despite of that observed particles are moving permanently.

In accordance with A. Einstein's theory, the curved space is caused by the gravitational fields of heavy bodies. Beside of any heavy body space is curved and degree of this curve, i. e. inadequacy of this plot of space to the laws Euclidian geometry, depends on quantity of this body. Yet, there were noticed some breaches in special theory of relativity. Thus in special theory of relativity postulated assumption that speed of light in vacuum is the same in all systems of coordinates. Furthermore, in quantum physics affirming that it is impossible predict some events. Instead of that there exists broad spectrum of possible trajectory of development along with different calculus of probability of realization. From a position of existence of 'parallel universes' (Multiverse) it might be affirm that each of these possible events correspond to the event which take place in other Universe.

But arises the question: why the speed of light beyond vacuum identical?

Moreover, in physics of time up to date there is no solution the following questions:

- If time is passing, why it passing in one direction?

- Are there quanta of time?

- If in some A. Einstein's equations assist closed like-time lines, how perfect is description of time in general theory of relativity?

Proceed from postulate 'things-in-itself', Kant rightly notes: "In space exists only what represented in it. ...Space is not empirical concept which deduced from external experience." I think that same may not say about time. Time is subjective attribution to the things definite characteristics based on the experience. Limitation of time by experience is quite natural because experience has been created by not-created by us 'things-in-itself' but by capabilities of human soul.

Time is very far from substance of 'things-in-itself', it can only artificially mark transitional position or state of 'things-in-itself'. Time is not occupied by anything, but space is occupied by the 'things-in-itself'. Seeming for humans' emptiness among things is really occupied, for example, by the energetic fields (the scalar, vector, tensor fields) and fields of gravitation (a massive body extends into the space around itself, producing a force on another massive body) or like these, which are pumping over powers to each other uninterruptedly, for all this, the sum of these powers has permanent quantity: increasing or decreasing of one power permanently coincides with decreasing and increasing of other power. Moreover, uninterrupted pumping over of powers is spirally developing process which fully occupies the space, has no source of beginning and ending, nothing adding to this process, not leaves the place for time, because continuity excludes intermittence and therefore time is not empirical reality. From empirical reality humans have artificially deduced transcendental quasi-reality which is no more than transcendental ideality. After that humans have artificially divided reflected transcendental ideality into segments.

Moreover, spirally developing process in space is smooth process without any qualitative leaps. Therefore, space is constant physical quantity but time is inconstant physical quantity. In this sense, I propose a hypothesis about the relative irreversibility of the second law of thermo-dynamics.

At the same time, I am suggesting general system of dialectics which could be mathematically formulated on the basis of Lobovikov's 'Uniting Parmenides' and Heraclitus' Philosophies by Means of Abstract Form Research in Values: A Logically Consistent Synthesis Emerging from Culture Algebra". He uses algebra of culture (algebra of values) for rethinking the relationship between philosophies of Parmenides and Heraclitus. I assume that, in its essence, philosophy is an abstract form research in values. Then he deduces logical consequences from this assumption. The system of abstract value forms is represented as two-valued culture algebra (Savaneli 2013).

In 1927 the German physicist Heisenberg came to the conclusion about impossibility of the simultaneous exact 
measuring of coordinate of particle and her impulse depending on speed, these sizes we can define only with the certain degree of probability. It is assumed in classic physics, that the coordinates of locomotive object can be defined with absolute exactness. Quantum mechanics substantially limits this possibility. The output of Heisenberg got the name of principle of correlation of to the vagueness that is the basis of physical interpretation of quantum mechanics. Essence of him is in the following: it is impossible simultaneously to have the exact meaning of different physical descriptions of micro-particles - coordinate and impulse. If we get the exact meaning of one size, then other remains indefinite fully, there are fundamental limits on measuring of physical sizes, characterizing behavior micro objects. Thus, concluded Heisenberg, reality differentiates depending on that, we look after it or no. A "quantum theory shuts out fully objective description of nature" already, he wrote. A measuring device influences on the results of measuring in a scientific experiment influence of man appears irremovable.

Foregoing principle of Heisenberg became for me as basis for rethinking by me categories of "Order" in general, and "Law" and "Order" in particular, that reflected in my numerous articles of $70^{\text {th }}$, in a monograph: "Law and order and Legal Practice"(1981), in doctoral dissertation: "Legal Order in Correlation with Positive Law from the point of view of understanding of Sense of Law" (1992), in subsequent monographs and $4^{\text {th }}$ different textbooks (1993-2009), and finally, in two volume of my monograph: "Global Order or Global Disorder, Academic Edition "Lambert", Vol. 1(449 pages) and Vol. 2 (553 pages), in English, Saarbruken, Germany, January-February, 2014", the prosecution of that occupied whole five years.

To the same, in connection with appearance of theory of the systems, as a new understanding of space as system of relations between objects, I gradually began to extend the spectrum of questions. Adhering to the theory of the systems, counterbalance system of positive law, and I entered the concept of the legal system, wrap-round two subsystems in kind of legal order and positive law, and educed the signs of their relative independence (1973); then regardless of positive law investigated the structure of legal order and educed a normative fact as leading factor of the system of legal order, in a difference from a legal fact as anchorman though formal elements of systems of positive law (1975); then, using judge experience, I defined the place of legal practice in the system of legal order and her decision role in progressive development of positive law (1981); then investigated normative nature of category of justice in the aspect of criterion of estimation of legal order and positive law (1985); then conducted the historical review of Georgian legal literature and educed original conceptions on the topic (1989); then in doctoral dissertation: "Legal Order in Correlation with Positive Law from the point of view of understanding of Sense of Law" (1992) I investigated a theme in the aspect of philosophy of law, public life and consciousness, sense of law, legal hermeneutics, efficiency of positive law, legal practice, fundamental human rights, theory of the self-directed systems (1992).

The Georgian word "Samkaro" means a space in which reign stable order. In Georgian understanding in universe has predominated law of order and it has substantially prevailed over law of disorder. In this sense, order is natural law of universe, while disorder is an exemption. Analogical processes have taken place in inanimate and animate nature, in human society and in human beings itself, and they also immanently includes some short phases of entropy which stimulates dialectical development of inanimate and animate nature, human society and human beings itself.

Any biological being, including human being, is the member of appropriate biological community. Any member of appropriate biological community, including human being, has independently submitted to the naturally and objectively established norms of appropriate biological community. Naturally and objectively established norms of appropriate biological community, including human community, regulate individual activities and mutual interactions of its members. Naturally and objectively established norms of appropriate biological community, including human community, regulate their members' individual activities and mutual interactions with the members of other biological communities, including human community. In the process of individual activities and mutual interactions of the members of inside and/or outside biological communities, including human community, has been appeared contradictions among them which are resolved by the naturally and objectively self-regulated and protecting norms of appropriate biological community, including human community. 


\title{
2. Space and Time, Order and Disorder in Human Being
}

\author{
"Space is an order of coexistence of bodies, and time - only order of sequences of events". \\ Leibniz \\ "We can find out no space that would be independent... it always is gap-filling space and nowhere differs from filling". \\ Hegel
}

At beginning of the twentieth century time appeared independent of the state of motion, leak with permanent speed in all frames of reference. However after experiments showed that time was slowed at high speeds of one frame of reference in relation to other. The deceleration, adopted by relativistic deceleration of time, is explained to in the special theory relativity. Deceleration of time was confirmed by many experiments, such as relativistic deceleration of disintegration of muons in the stream of ultra-rays and deceleration of atomic clock aboard a space shuttle, rocket and airplanes of the clock relatively set on Earth.

Conception of space and time in the first was universally recognized after advancement of by Lobachevsky of Euclidean geometry and general special theories of relativity of A. of Einstein. Lobachevsky in-process "Beginning of geometry" proved - non-conflicting geometry different from being considered only to possible Euclidean geometry is possible. A scientist showed that space properties depended on properties of locomotive matter, final answer for a question about properties of space, in opinion of Lobachevsky, astronomic supervisions must give. Some later, in 1867, work of Riemann went out in light "About hypotheses, lying in founding of geometry" in that he also offered the idea of dependence of space properties from material to the Physical space can be distorted, however whether it is distorted actually, must, in opinion of Riemann, to decide an experiment.

Moreover, A. Einstein came to the conclusion about universality and generality of principle of relativity: not only mechanical but also electromagnetic inertial systems are equal in rights on attitude toward each other, and events simultaneous in one system will not be simultaneous in other, locomotive the relatively first. Confession of relativity of measuring of sizes of bodies became investigation of this conclusion: the length of body, measured by different observers' locomotive in relation to each other with different speeds, must be different. The same belongs and to time: time of flowing of process will be different, if to measure him by hour's locomotive with different speeds. At approaching to velocity of light all processes in the system are slowed, and the sizes of bodies grow short, if to watch them, being outside the most locomotive system. Thus, in the special theory of relativity the sizes of bodies and time of flowing of processes are put in direct dependence on the frame of reference, their measuring is made in that. Appeared, that a physical process can be described only in relation to the certain frame of reference, the choice of that depends on an observer. Otherwise speaking, for adequate description of the relativistic phenomena factor of observer became substantial. However, in spite of convincing enough proofs of general theory of relativity and her universal recognition, the attempts of creation of alternative theories of gravitation and gravitation proceed in physics.

The Great German physicist Planck showed the researches, that the radiation of energy took place discretely, by certain portions - quanta energy of that depends on frequency of light wave. The theory of Planck did not need conception of ether and overcame contradictions and difficulties of electrodynamics of Maxwell. The experiments of Planck resulted in confession of ambivalent character of light that possesses corpuscular and wave properties simultaneously. Clear that such conclusion was incompatible with presentations of classic physics. The theory of Planck put beginning to new quantum physics that describes processes a leak in micro world.

Partially leaning against the ideas of Planck, A. Einstein offered the photonic theory of light, in obedience to that light is thread of locomotive quanta. The quantum theory of light (or photonic theory) examines light as wave with an irregular structure. Light is thread of indivisible light quanta-photons. The hypothesis of A. Einstein allowed explaining the phenomenon of photo-effect is beatings out electrons from a substance under the action of Hertzian waves (German physicist Heinrich Rudolf Hertz). It became clear that an electron beaten out by a photon only in case that energy of photon suffices for overcoming of force of cooperation of electrons with an atomic kernel.

Explanation of photo effect leaned, besides the quantum hypothesis of Planck, also on new ideas about the structure of atom. In 1911 the English physicist Rutherford offered the planetary model of atom. This model presented an atom as positively charged kernel the negatively charged electrons run around round that. Arising up at motion of electrons on orbits force is counterbalanced by attraction between the positively charged kernel and negatively charged electrons. The general charge of atom is equal to the zero, as charges of kernel and electrons are equal to each other. Almost all mass of atom is concentrated in its kernel, and mass of electrons is insignificantly small. By means of planetary model of atom the phenomenon of rejection was explained alpha of particles at passing through an atom. As sizes of 
atom is great as compared to the sizes of electrons and kernel, so far as alpha a particle without obstacles passes through him. A rejection is observed then, when alpha a particle passes close from a kernel, in this case the electric pushing away causes her sharp deviation from a primary path.

The Great Danish physicist Bohr offered more perfect model of atom, complementing the ideas of Rutherford new hypotheses. The postulates of Bohr sounded as follows: 1. Postulate of steady-states. An electron accomplishes in an atom steady orbital motions on stationary orbits, not emitting and not taking in energy. 2. Rule of frequencies. To go across the electron capable from one stationary orbit to other, here emitting or taking in energy. As energies of orbits are discrete and permanent, then in transition with one of them on other certain portion of energy is always emitted or taken in.

In this respect, it is impossible to go round attention the concept of entropy. In the middle of $19^{\text {th }}$ century the German physicist Klausius entered a new concept is entropy. It was entered in the beginning in an order to distinguish convertible processes from irreversible one. It was known that entropy increases only as a result of irreversible processes. But later has been turned out that entropy can be examined as an internal evolution of the isolated system, because the isolated system in time spontaneously goes across the equilibrium state. Thus entropy of the system droningly increases as far as approaching to the thermodynamics equilibrium, and the state correspond equilibrium with a maximum of entropy. However, isolated systems it is an illusion. Counterbalance of theory of entropy, although many systems are in the non-equilibrium state, but it only is their temporal stages on the way to the equilibrium state due to neighboring systems.

Exactly due to them any system sooner or later will come to the equilibrium. Although from the presence of great number of parameters all of it not too simply, especially for the difficult systems, because at aspiration to equalize a difference in one parameters, there will be gradients of other parameters, however at nature not two positions of asymmetry and great number (gravitational and electromagnetic the fields, temperature, pressure, closeness, concentration etc.). It turns out thus, that any system can possess in a number of the movable equilibrium states depending on internal one, and in particular from external terms.

Space is filled by energy. In this sense space and energy are identical. Energy is a grandiose thread wrap round all processes in Universe, and all processes what be going on in these systems are sources a feed in this general thread.

Moreover, energy flows in space through reason to investigation. The impression turns out, that energy is pulled in by reason and, vice versa, made more compact in a that place, where investigation is located. Energy is expended or appears in any process. Therefore there are grounds for identifying of thread with some substantially thread, source of which there are any non-equilibrium, irreversible processes including the processes, attended with the changes of energy and thermodynamics entropy of the systems. An universe and her subsystems are not isolated, i.e. necessary condition only actions of the second beginning of thermodynamics is absent; in the wild there are constantly operating reasons impedimental to growth of entropy.

The height of number of various consequence results in realization of all greater number of the possible states of the system. There is a loss of the good organization brought in the system by some reason.

However, the closeness of energy anymore wherein transients has gone. With growth of entropy (chaos) the closeness of energy increases. However, when an "order" decreases, "other" part of space, aspiring to acquire of stationary position, begins "assuming" remained energy. This is the law of equilibrium, resulting in order of system on the whole. Consequently, entropy is not law, but transient (phase) of transformation of energy, and in our too case, disorder is a not law, and transient (phase) of transformation from one order in other order.

Therefore, second law of thermodynamics it is a phase of single, permanent and ubiquitous synergetic process. In other words, it is a phase only border of transition of any energy from one state in other in permanent and ubiquitous synergetic process. And consequently, entropy is too similar phase of single, permanent and ubiquitous synergetic process. Consequently, due to such physical property energy brings in the vital beginning in the World, prevents to the offensive of its thermal death and provides existing in him harmony of life and death. And so, the change of the state and properties of substance can take place not so much in course of time, but under operating of energy on him. The first circumstance corresponds to the laws operating in passive to geometrical energy, and second - it contingently it's active, physical properties.

The special experience showed that processes, defiant the height of entropy of substance, radiated energy. Thus, at a being near-by substance put in order its structure. Apparently lost from the continuing process of entropy of substance, its good organization in greater or less part is "filled" by energy of other substances. It means that energy carries information about events that can be passed to other energy. Almost direct proof drawn conclusion higher turns out that the action of closeness of energy diminishes entropy and counteracts to the ordinary course of events. The most various properties of substance can change under the action of energy. However for researches of active properties of 
energy and essence of its operating on substances, follows, certainly, stopped for those properties substances the changes of that can be registered easily and exactly. Totality of undertaken studies shows that the state of substance depends not only from influence of near processes, but also from the change of general background of closeness of energy, which originates from the wide circle of geophysical processes and many space phenomena. Influence of geophysical factors must result in seasonal and day's motion of changes of the state of substance. A quantum theory also contains into itself obvious conceptual paradoxes that even after one hundred years stay unsolved. An electron shows up as a wave and as a particle. Light behaves similarly. What be more, a theory gives the statistical predictions of subatomic behavior only. All of it specifies on that a quantum theory does not tell complete history. In the total, in spite of her success, there are many experts that is convinced, that a quantum theory hides something substantial about nature, about what we need to know.

\section{However, where must we search that not right in quantum mechanics?}

Predictions of general theory to relativity counterbalance of quantum theory are in tune with supervisions with the large degree of exactness. Supervisions on these questions extend from falling bodies and light on Earth, to the gone into detail motion of planets and their moons, to the scales of galaxies and accumulations of galaxies. Einstein that certainly thought of it more than any other underlined that we must distinguish two types of theories. These are theories of principles and structural theories. The theory of principles sets the system of looks that does possible description of nature. On determination, a theory of principles must be universal: it must be applicable to everything, as it sets a basic language that we use, to talk about nature. There cannot be two different theories of principles applicable to the different areas of nature. As the world is single, all, in final analysis, co-operates with all other, and there can be only one language used for description of this cooperation. Quantum theory and general theory of relativity both are the theories of principles. One time so, logic requires their association. An exit from the reserved circle is urgent task of theoretical physics. The question must is about the association of general theory of relativity and quantum theory in one theory that can apply on the role of complete theory of nature. It is named the problem of quantum gravitation.

But how can we to reconcile together the general theory of relativity and quantum theory, and in parallel with the problem of unitization?

In Euclidean geometry, if two straight lines are initially parallel, they will never meet. But two lights shining, that were initially parallel, can meet in the real world, as, if they pass for both sides from a star, they will deviate to direction to each other. So that Euclidean geometry is not faithful for the real world. What be more, geometry changes constantly, as a matter moves constantly. Thus, the double unitization set by principle of equivalence becomes a triple unitization: all motions are equivalence, as soon as the effects of gravitation are taken into account, gravitation is indistinguishable from acceleration, and the gravitational field teams up with geometry of space. Geometry of space and time changes and evolves, as well as all other in the wild. Different geometries of space describe histories of different universes. We no longer have the fields moving in the fixed base-line geometry. We have clots of the fields that all co-operate with each other, all are dynamic, and all influence on each other, one of that is space geometry.

Most physicists came to the conclusion, that physics of particles rather hierarchical, then equipotent. Their forces and the masses of are distributed in the wide range of sizes, forming the hierarchy of gravitation from strong to weak. On a top there is Planck's mass that over identical to energy. On similarity of hierarchy of norms of positive law such system is symmetric. Symmetry essentially prevents the extrusion of their masses. One of methods to limit freedom of particle there is binding of her behavior to other particle, whose behavior is celled in some limits. However, close system did not govern, and exception. Consequently, by virtue of the second law of thermodynamics open system always diminished that to become reason of the proportional strengthening of border-line particles that in final analysis saves balance of the system on the whole. There is the second law of thermodynamics in this quality is not vulnerable.

In respect of the question: does time possess in general by energy? My answer is simple and laconic: space is filled by power processes. If to assume that, it seems that such processes are temporal, then means that space temporally, and space depends on time i.e. time source of existence of space, and time can exist and without space, and space without time. What be more, an order and disorder in space are inferior to the dictate of time. But it not so, and quite the reverse!

Counterbalance it might be ask following:

Is it really possible to say that space it is stops or stopping during time; space it that alternately stops and begins again; space it then what alternately does function and does not function or alternately does not function properly? No!

Is it really possible to say that space is what being going on with irregular intervals; that are not continuous or steady? No!

Is it really possible to say that space it something not what be going on is regular or permanent; something what be going on with stops and repeated starts or with periods; something irregular? No! 
Is it really possible to say that space it is a start, stop, and undertaking again; not permanent or unsteady? No!

My first conclusion is unambiguous: word the irregular (intermittent) is used to the concept of time, but not to space.

My second conclusion is unambiguous: a word "continuous" is used to the concept of space, but not - to time.

Thus, time is a period artificially divorced by man from the chain of uninterrupted moving energies that fill the space.

As conclusion to this part of article, I am suggesting general system of dialectics which could be mathematically formulated on the basis of Lobovikov's 'Uniting Parmenides' and Heraclitus' Philosophies by Means of Abstract Form Research in Values: A Logically Consistent Synthesis Emerging from Culture Algebra". He uses algebra of culture (algebra of values) for rethinking the relationship between philosophies of Parmenides and Heraclitus. I assume that, in its essence, philosophy is an abstract form research in values. Then he deduces logical consequences from this assumption. The system of abstract value forms is represented as two-valued culture algebra.

\section{Legal Order and Legal Disorder in the Light of Synergetic Theory}

From the philosophical point of view the synergetic is called often as "a global evolutionism" or the "universal theory of evolution" giving a uniform basis for the description of mechanisms of emergence of any innovations, equally suitable for the description of any operations of regulation and optimization: in the nature, in equipment, in society etc. By the way, in relation to the position of $\mathrm{Ch}$. Sherrington I called synergetic, or integrative, the coordinated influence of nervous system (spinal cord) at management of the muscular movements. (The device of synergetic is combined from different branches of theoretical physics: nonlinear equilibrium thermodynamics, theory of accidents, and theory of groups, tensor analysis, differential topology, and non-equilibrium statistical physics).

At the same time, as it is well known, essential attributes of human being are following: a) Human being is a rational being; b) Human being is an irrational being; c) Human being is a social being; d) Human being is a creative being; e) Human being is a words producing being; f) I would be added that human being is being that previously plan or lay out their future actions.

A difference from wild-life, humanity not only part of wild-life but also free will creature, as a result, he simply is not written into the chains of cooperation of energies.

Concerning human being dialectical, constant and continuous interaction of the elements within each human community can be divided into two groups: on the one hand - these are elements of the normative order, but on the other - these are elements of the normative disorder. So normative order and normative disorder generally represent two sides of the community who are in a dialectical, constant and continuous conflict.

At the same time, their contradiction has two forms:

1) Normative order and normative disorder presuppose and stipulate each other;

2) Normative order and normative disorder exclude and negate each other. In this sense, every human community is characterized as self-contradictory and self-negated entity that, on the other hand means finding a human community in a dialectical, constant and continuous self-changing, more exactly - in self-motion state. At the same time, in accordance with the law of synergy such contradiction and self-motion includes dialectical, constant and continuous mutual transition and exchanging process of energies within each human community and between human communities of society in whole.

However, there is much more order in the world, what it is necessary for existence of man. In Universe the permanent order of counterbalance dominates to temporal disorder. Only a man causes disorder in the natural order. This axiom became basis of introduction of various codes of conduct.

In the strong sense only man and is the generator of entropy. Unfortunately only humanity executes entropy activity, because such activity makes one of parties of life. It is necessary to face the truth! On the other hand, there is no sense to tear away a man from other organic world. As well as at all organic life, aim of existence of humanity on the whole is maintenance of kind and no more. One time so, it turned out that on Earth favorable terms were created for the origin of the high-organized life.

Theoretically, any human community is an organization whose members, regardless of their number, are interconnected by norms of behavior.

In the process and as a result of compliance with the norms of behavior by the members of the community in the organization develops certain normative order i. e. normative order of their interaction.

In the process and as a result of non-compliance with the norms of behavior by the members of the community in the organization develops certain normative disorder i. e. normative disorder of their interaction. 
Practically, in any human society are coexisting normative order and normative disorder, elements of which dialectically, constantly and continuously interact with each other in form of mutual transformation. The degree of parameters and correlation of normative order and normative disorder in form of mutual transformation in any human community enables us to figure out identify and evaluate the state of the organization as a whole from the point of view of being in it the level of presence normative order and normative disorder, including level of entropy.

In avoidance of catastrophic consequences of "not inscription" of free will in the chain of cause-effect connection, humanity "thought" the certain codes of conduct of man in society and normative procedure of realization of such codes. But as any system as an order of cooperation in time loses the primary good organization and it gets older in accordance with the second beginning of thermodynamics and there is passing to more credible state, humanity additionally "thought" of the abstract codes of conduct of man in society in kind of positive law (constitution, constitutional and organic laws, current legislation etc.) (Savaneli 2013).

From the position of sociology of law, the picture is looks like in following image. Usually participants of social relations are acting in accordance with appropriate social norms, beforehand subjectively know nothing or mainly nothing how much his/her action is strictly accord or not to the norms of positive law. On this level we have the unity of social norms and social acts which might be called as normative facts. The normative facts in summary represent established norms of social order. At the same time, objectively established norms of social order might be contradicted to the norms of positive law, and positive law has non-compulsory attempt to reconstruct partially the norms of social order.

From the position of legal theory, the picture is looks like in following image. First of all, usually participants of social relations are acting in accordance with the distributed by them mutual obligations and related to them rights, beforehand subjectively know nothing or mainly nothing how much his/her action is strictly accorded or not to the norms of positive law. On this level we have the unity of legal norms (mutual obligations and related to them rights) and legal acts of participants of normative relations (legal facts). The legal norms + legal facts = legal normative facts which in summary is content of objectively established norms of legal order.

In legal space the catalyst of bringing the political and economic systems presents naturally included in the legal order the self-governing forces not giving to the entropy processes to take upwards above the processes of order, and simultaneously giving to the State to create artificial (legislative, executive and judicial) powers for the achievement of legal order in the civil, political, economic, social and cultural space (see below).

At the same time, objectively established norms of legal order in process of movement always will contradict to the norms of positive law, and positive law has non-compulsory attempt to reconstruct partially the norms of legal order because between them located free-will of human beings. That is regulatory function of positive law to the legal order. As the continuation of the this stage of regulation, objectively established norms of legal order (mutual obligations and related to them rights and legal acts) might be so contradicted to the norms of positive law that positive law cannot able to reconstruct partially the norms of legal order by the non-compulsory means and necessity of conflict resolution and prevention dictate to the state to use compulsory means through the application of legislative, executive and judicial powers against wrongdoers. That is partially protectoral function of positive law to the legal order.

Therefore, in state-regulated society are established two spaces - positive law and legal order. In other words, positive law is "Law in the Books"; legal order is "Law in the Life".

At the same time Positive law - "Law in the Books" and Legal Order - "Law in the Life" have different contents from the point of view of role of human rights in the process of their functioning.

Study of positive law includes analyze of:

- Procedural norms of passing of laws and material norms of construction of laws;

- Procedural norms of application of laws and material norms of construction of administrative decisions;

- Procedural norms of law-suit of courts and material norms of construction of judgments.

In this sense a positive law is a unit of general procedural norms and material norms, for example, code of civil procedure and code of civil law, code of administrative procedure, code of criminal procedure and code of criminal law, and etc. General procedural norms and material norms of each space of positive law are not two independent branches but continuation of each other.

Study of Legal order includes analyze of:

- Established practice of passing of laws and material norms of construction of laws;

- Established practice of application of laws and material norms of construction of administrative decisions;

- Established practice of law-suit of courts and material norms of construction of judgments.

In this sense a legal order is a unity of established practice of application of concrete procedural norms and material norms, for example, unity of established practice of application of code of civil procedure and code of civil law, code of administrative procedure, code of criminal procedure and code of criminal law, and etc. Concrete procedural 
norms and material norms of each space of analyze of order are not two independent branches but continuation of each other.

More deeply, distinctions between public law and private law at the level of positive law are not substantial, but distinction between public legal order and private legal order at the level of normative are substantial.

At the level of positive law distinctions between public law and private law is only theoretical and conditional but not practical and unconditional.

At the level of legal order distinction between public legal order and private legal order is practical and conditional (but not theoretical and conditional).

If at the level of positive law procedural law theoretically and conditionally preceded to material law, at the level of legal order material law has preceded to procedural law, because the participants of legal relationships can relinquish its right to dispute the case through the using of public procedure. This is a reality.

Since 1975 in my works I had an attempt to prove that:

1) On the one hand, distinction between the private positive law and private legal order, and distinction between the public positive law and public legal order, has controversially distinct character. The private legal order as a summary of legal facts made by private persons is an independent, and precedes the private positive law as a summary of norms of positive law. Simply, the private positive law (norms of positive law) is a continuation of private legal order (legal facts). The public positive law as a summary of norms of public law is independent, and precedes the public legal order as a summary of norms made by public bodies. Simply, the public normative order (norms of public bodies) is a continuation of public positive law (norms of public law);

2) Generally, the Positive Law i.e. private positive law and public positive law, and Legal Order i.e. private legal order and public legal order, particularly, private positive law and private legal order, and public positive law and public legal order independently and together as cross-sectional orders have to be in permanent mutual transformation, spirally, evolutionary and endlessly development as the guarantee of the peace on Earth.

Both norms of legal order i.e. norms relating to the real subjects of legal relations (empiric reality) and norms of positive law i.e. norms relating to the ideal subjects of public relations (transcendental ideality) serve of reconciliation of natural necessity (natural human rights) within the framework of the folded legal system on the whole. Both - the real subjects of legal order and ideal subjects set legal norms, in first case - "real", and in the second "ideal" norms are subjects of legal system. However, norms of positive law i.e. norms relating to ideal (future) subjects of public relations in final analysis depends upon the norms of legal order i.e. norms relating to the real subjects of public relations, in other words - upon of empiric public reality as a source of transcendental public ideality.

In respect of structure of norms of legal order as parts of empiric reality is the unity of facts (hypothesis) and mutual rights and duties (dispositions) of parties of certain normative relationship. In philosophical terms: legal order is an area of empirical reality, in which the real participants of legal relationships set mutual right and duties. Creation of mutual rights and duties consists of two parts: facts of creation of mutual rights and duties and creation of norms of behavior i.e. rights and duties by the real participants of normative relations. In this aspect my position in a root differs from position of Adolf Reinach and Leon Petrażycki, but in greater part similar with position of George Naneishvili. (Naneishvili, 1929, 1986).

In respect of structure of norm of positive law as part of transcendental ideality, it contains the hypothetical facts artificially extracted by a legislator and artificially applies to the natural facts. Figuratively, legal norm of positive law is the unity artificially formulated of facts and artificially formulated rights and duties. In other words, positive law it is a part of transcendental ideality in order to transform of empiric reality, for that a legislator artificially distinguishes hypothetical facts and artificially mutual rights and duties for the future participants of legal relationships that realized, after which they grow into the cursor of elements of legal order.

For the purpose of argumentation suggested by me the Applicability of Synergetic Theory to the Living Creatures and Human Being, previously it is necessary to make clear distinction between positive law and legal order.

Notably that the English word "Order" and Russian word "Порядок" differ from Georgian "Tsesrigi". The Georgian word "Tsesrigi" is word-combination of two words - "Tsesi" and "Rigi", accordingly translatable as a "Rule" and "Row". On maintenance the Georgian word "Tsesi" is none than norm i.e. rule of behavior, and "Rigi" none another than row of implementation of norm (rule of behavior). In other words this is a process of organization of human behavior. Consequently, the Georgian word "Tsesrigi" in integrity has exceptionally original normative maintenance, regardless of that confesses or not such quality by a positive law (more concretely see below concerning the notion of normative facts: facts + norms).

Positive law is only "state law in books", while legal order is "state law in actions" + not-restricted by the positive law "social law in actions". 
Particularly, legal order is the process and result of observation by the state bodies and private persons positive law + the process and result of observation by the private persons not-restricted by the positive law "social law in actions". ("Social Law" includes different norms of contract, religion, ethics and etc.). Accordingly, legal disorder is the process and result of non-observation by the state bodies and private persons positive law + the process and result of non-observation by the private persons not-restricted by the positive law "social law in actions".

More broadly here it is distinction between positive law and legal order.

Positive law is a set by the state not contradicted to the fundamental human rights and freedoms part of general social norms i.e. a «just state law in books», operating along and together with other contradicted to the norms of positive law other general social norms, which in aggregate make a «just social law".

Legal order is a «just state law in actions» i.e. process and result of observance of positive law by the public and private persons + process and result of observance by the public and private persons un-contradicted to the norms of positive law and other general social norms actions, which in aggregate make a «just social order". (Savaneli 1977).

Accordingly, in contradiction to the legal order legal disorder is a «unjust state law in actions» i.e. process and result of inobservance of positive law by the public and private persons + process and result of inobservance by the public and private persons un-contradicted to the norms of positive law and other general social norms actions, which in aggregate make a «unjust social order".

In this sense, in positive law time is absent, as a positive law essence clean "ought to be", in other words a positive law is judgment about that what must behave physical or legal persons, but not what they are behaving. Simple example is a structure of norm of positive law which mainly consists of two words: "if" and "must" that is certainly expressed in next judgment: "if that (hypothesis) will happen, then persons must (disposition) behave definitely". (Savaneli 2008).

In the space of positive law norms are oriented on abstract (not exactly individual) physical or legal persons, and in such kind they are not temporal. In positive law norms maybe will fall under the action of physical or legal persons only in case of abstract judgment: "if (hypothesis) something will happen, then persons must (disposition) behave definitely". Physical or legal persons are only potential subjects of certain legal relationships. Here interaction of "if" (hypothesis) and "that"(dispositions) fall under the category of "Possibility".

In the space of legal order norms are oriented on exactly individual (not abstract) physical or legal persons, and in such kind they are temporal that fall under the action of concrete judgment: "if (hypothesis) will happen, then persons must (disposition) behave definitely". Physical or legal persons are real subjects of certain legal relationships. Here interaction of "if" (hypothesis) and "that" (dispositions) fall under the category of "Reality".

In legal order the space is constantly presented by mutual rights and obligations of individual physical or legal persons as subjects of legal relations before and after implementation by them certain norms of positive law. In the process of implementation of certain norms of positive law legal relations among them in space of legal order temporally replaced by mutual rights and obligations specified by the certain norms of positive law that prevailed over mutual rights and obligations of individual physical or legal persons as subjects of legal order.

So, I differentiate notion of subject of legal order and notion subject of positive law.

As evidence I will represent a few examples. Generally the birth of child it is a natural process, but not irregular phenomenon. From that natural process a legislator artificially chooses and distinguishes a certain moment, for example, dissociating of living raft from womb of mother and this moment names a fact to that a legislator binds the origin of certain rights for every child and duties of corresponding persons in the future. In this kind every child is subject of positive law. After the fact of born of individual child he/she is becoming as natural subject of legal order, and this fact is normative fact despite of its recognition by positive law. This normative fact serves as basis of its recognition by positive law as subject of positive law. Death of every man it is a natural process, but not irregular process, and the fact of death is normative fact which means that he/she already is not subject of legal order. From this natural process a legislator artificially chooses and distinguishes a certain moment, for example, clinical death and this moment a legislator binds with stopping of certain rights and duties, and origin of certain rights and duties of corresponding persons. After the fact of death of individual person he/she is becoming as natural object of legal order, and this fact is normative fact despite of its recognition by positive law. After the fact of death of individual person he/she is becoming artificial object of positive law. So, normative fact of death serves as basis of its recognition by positive law as object of positive law.

In philosophical terms: legal order is essence of empiric reality, and related to it positive law is essence of transcendental ideality. So such different levels of "things in itself" mean: from one side - empiric reality, and from other transcendental ideality that both evidently represent the field of legal life of humanity.

If we use Hart's terms, legal facts of private persons might be nominate as primary rules, while legal acts of public bodies - as secondary rules. Like Austin I think that one of the central tasks of jurisprudence is to provide a theory, which describes the positive law as it 'is 'in a value neutral manner - separate from seeking jurisprudence to provide 
guidance on how the positive law 'ought to' function - partly in order to overcome some of the difficulties in discovering what law is. Austin describes the position as such: The existence of the law is one thing; its merit or demerit is another. Whether it be or be not is one enquiry; whether it be or be not conformable to an assumed standard, is another enquiry. A law, which actually exists, is a law, though we happen to dislike it, or though it varied from the text, by which we regulate our approbation and disapprobation. (Austin 1968).

Concerning of applicability of synergetic theory to the legal system, I would like to underline the following.

The synergetic theory of legal system (legal order + a positive law) - the theory about difficult legal system - the interdisciplinary direction of legal science studying the general regularities of the phenomena and processes in nonequilibrium and nonlinear system of society on the basis of properties of self-organization and self-reproduction inherent in it.

The basic concept of legal system - definition of structure of legal system as the state which is constantly resulting from multiple and ambiguous behavior of multi-element structures or multiple-factor social environments in society which don't degrade to averaging of thermodynamic type, standard for the closed systems, and develop owing to openness, inflow of energy and an exchange of energies from the outside and inside, nonlinearity of internal processes, emergence of the mode of their temporary aggravation, and then its continuous transition to a steady state on a spiral, in principle excluding entropy. Eventually, legal system steady system of transition of one cycle of development in another in a spiral that leads to formation of new structures including more difficult, than initial. Formation of new structures has regular, wave character, and it is called as auto wave process in legal system.

Nonlinearity of legal system will consist in the following. When nonlinear dynamic systems unite, new education isn't equal to the sum of parts, and forms system of other organization or system of other level.

Upon transition from the disorder state to a state ordered legal system all developing subsystems behave equally that the generalized synergetic device is suitable for the description of all variety of their evolutions. Thus, the developing subsystems are always open and exchange energy within legal system at the expense of what there are processes of legal orderliness and self-organization.In non-equilibrium conditions relative independence of elements of legal system gives way to "corporate" behavior of elements: in balance blitz elements interact only with next, thus they take into consideration also experience of not adjoining elements therefore all legal system entirely passes in the coordinated and equilibrium state. In conditions of legal system, far from balance, bifurcation mechanisms only of short-term points of bifurcation as the intermediate moment of transition to rather long-term mode of legal system start operating.

Therefore, the synergetic theory explains process of self-organization of legal system as follows.

The legal system has to be open. The closed system according to laws of thermodynamics has to come finally to a state with the maximum entropy and stop any evolutions.

1. The open legal system has to be rather far from a point of thermodynamic balance because in a balance point the system possesses the maximum entropy and isn't capable to any self-organization. In the situation close to thermodynamic balance, any system even more will come nearer over time not to dynamic balance and will cease to change the state and is becoming numbed.

2. As the fundamental principle of self-organization of legal system emergence of new legal order and complication of systems through temporary (casual) deviations of subsystems and their elements serves. Such temporary (casual) deviations usually are suppressed in all dynamically stable and adaptive with systems at the expense of the fresh feedback providing preservation of structure and a condition of system, close to balance. In more difficult open systems, thanks to energy inflow from the outside and to strengthening of nonequilibrium though deviations increase over time, collect, cause effect of collective behavior of subsystems and their elements that, eventually, lead to "shaking" of a former order, and through rather short-term chaotic condition of system lead to destruction of former structure, but by law evolutions by means of mobilization the new passion - day forces promotes emergence of new, more "progressive" legal order. Otherwise effects from synergetic interaction will be insufficient for emergence of collective behavior of elements of system and by that self-organization emergence.

3. The stage of self-organization comes only in case of prevalence of the positive feedback operating in open system over negative feedback. In self-organizing, in the evolving system the arisen positive changes aren't eliminated, and collect and amplify owing to the general reactivity of system that can lead to emergence of a new order and the new structures formed of some elements of the former, destroyed system. Mechanisms of phase transitions of substance or formation of new social formations are that, for example.

At the description of evolutionary processes it is necessary to refuse symmetry of time, characteristic for completely determined and reversible processes in classical mechanics. Self-organization in difficult and open systems to which life and reason, in particular legal system belong, lead to irreversible destruction old and to 
emergence of new systems and their structures whereas non-decrease of entropy in the closed systems causes existence of "a black arrow of time" in society.

4. At the description of evolutionary processes it is necessary to refuse symmetry of time, characteristic for completely determined and reversible processes in classical mechanics. (Savaneli 1978).

In this sense, I come to the conclusion that the synergetic theory is fully applicable to legal system (legal order + positive law), and therefore, to legal system neither the second beginning of thermodynamics, nor Prigozhin's theorem of a minimum of speed of production of entropy are directly inapplicable, and the general mechanism everywhere of the direction of synergetic that is dialectic evolution observed in the nature is applicable. Temporally and non-equilibrium character of legal system is a necessary condition of emergence of the new organization, a new legal order, that is - progressive development of legal system in general.

Self-organization in difficult and open systems to which life and reason, in particular legal system belong, lead to irreversible destruction old and to emergence of new systems and their structures whereas non-decrease of entropy in the closed systems causes existence of "a black arrow of time" in society. However, the permanent problem of jurisprudence is transition of the mutual transformation of model of coexisting normative order and normative disorder into the model of mutual transformation of model of coexisting legal order and legal disorder through positive law.

The greatest mistake of canonical jurists is that they identify legal order and positive law, while legal order is the existence order that it is. More concretely, legal order is the established by the private persons and public bodies real order of distribution of mutual obligations and correspondent them rights among them. At the same time, legal order is such order which has legal pretension to be ideal order i.e. positive law. However, positive law is non-existence order that ought to be. More concretely, positive law is the established by the legislator ideal order of distribution of mutual obligations and correspondent to them rights among private persons and public bodies. At the same time, positive law is such ideal order which has legal pretension to be real order i.e. legal order. (Savaneli 2003).

Accordingly, it is necessary to differ: statuses of subjects of positive law and statuses of subjects of legal order. State, church, individual, group of individuals and like subjects have two statuses: statuses of subjects of positive law (static status) and statuses of subjects of legal order (dynamic status). Translating into philosophical language, legal order is a 'phenomenological realism', while positive law is a 'phenomenological idealism'. Philosophical point of departure of distinction of legal order and positive law based on the distinction between 'subjective existence and objective existence', using by Husserl, and especially Heidegger notions. But made by them such distinction excludes their interaction in the aspect of mutual and endlessly transformation using by me the method of Hegel. In that sense, Husserl comes to a stop in the middle of road, has remaining their isolation.

Remake phenomenological method of Husserl, Heidegger purifies phenomenology of Husserl from the admixtures of 'objectivism'. At the level of 'existence philosophy' Heidegger has exposed individual-personal character of 'subjective existence', and does not using dialectical method, he fully excludes any possibility of coexistence with 'objective existence'. As a result has erased crisis of 'existence philosophy'.

However, existentialism cannot argue freedom, duty and responsibility, and just because, I have proposed dialectical model of mutual and endlessly transformation of legal order and positive law. As a result, it has been established natural legal order, and artificial positive law. In this sense, positive law is not legal order but potential legal order i.e. legal order establishing of which is the end of State. Legal order is legal reality. After that is becoming apparent transcendental tendency of mutual transformation of legal order and positive law. Such transcendental tendency produces a necessity to elaborate a model of their mutual transformation based on the laws of dialectics. The name of model of mutual transformation of legal order and positive law is Dialectical Jurisprudence.

Controversially, using dialectical method I have proposed not only coexistence of 'subjective existence' and 'objective existence', but their mutual transformation.

Controversially, using dialectical method at the level of jurisprudence I have proposed mutual transformation of legal order and positive law.

I am drawing distinction between legal acts of public bodies and legal acts of private persons. If Ehrlich point sought to make was that the "living law" regulates social life is different from the norms for decision applied by courts, I seek to make is that the "living law" envelops both - norms that regulate social life and norms which regulate activities of courts and other public bodies, and these norms have been differentiated in the frameworks of "living law" using Ehrlich's term. The norms which regulate social life are the established legal practice of activities of private persons. In this sense, I think that Legal Order is "living law". So, the norms which regulate social life and norms which regulate activities of courts and other public bodies (including those disputes that are brought before judicial or other public bodies) have enveloped by legal order, and in their unity represent life of community i.e. economic, social, cultural, civil and political life of human communities. 
'Living law' is a framework for the routine structuring of legal relationships among private persons and/or their groups, and private persons and their groups and/or public bodies and among public bodies through the distribution of mutual obligations and reflective to them rights. Its essence is also dispute and litigation, which includes mediation and co-operation.

My position is that the material source of positive law is legal order, which envelops plural forms of economic, social, cultural, civil and political relationships and they may conflict. Legal norms are, thus, regarded as socially fundamental. However, in legal order, as well as in any system, gradually gain upper the natural process of entropy which naturally provoke emergence of 'instinct' of self-defense through the seeking and striving for neutral outside power as guarantee of its stability and sustainable development. As one of forms of natural being, and analogically to it human beings, naturally such power have granted to the recognized or elected one human being or group of human beings.

In the end, Humankind creates a States, particularly legislative, executive and judicial powers, and sets up for them positive law is a system of laws according to which a state, particularly legislative, executive and judicial powers, are governed. At the level of positive law jurisprudence has statically interpretative i.e. theoretical characteristic. At the level of legal order, jurisprudence has dynamically interpretative i.e. practical characteristic. More clearly, at the first level, jurisprudence interprets what the positive law 'is' i.e. what it demands from the private persons and public bodies theoretically. At the second level, jurisprudence interprets what the legal order 'is' i.e. what it demand from the private persons and public bodies practically. In other words, at the first level, jurisprudence creates a theoretical model of activity of private persons and public bodies, but at the second level, jurisprudence creates a practical model of activity of private persons and public bodies.

Moreover, in distinction of positive law, legal order substantially has horizontal but not vertical structure. In philosophical aspect, positive law is not based on horizontal legal reasoning but on vertical legal reasoning. In philosophical aspect, legal order is not based on vertical legal reasoning but on horizontal legal reasoning. In philosophical aspect, positive law is not based on horizontal legal reasoning but on vertical legal reasoning.

At the same time, legal order has the power of authority, while positive law - the authority of power. Deeply roots of not only private positive law but public positive law in 'action' are in the wombs of legal order. Legal order as summary of legal facts causally gives rise to positive law, but positive law causally is not gives raise public positive law. Legal life of society is an objective process of dialectical transformation of legal reality (legal order) into legal possibility (positive law), and legal possibility (positive law) into legal reality (legal order). In other words, legal life of society is an objective process of dialectically mutual transformation of legal reality (legal order) and legal possibility (positive law), because motive force of such processes are the objective wills of participants of legal relations in kind of private persons (individuals and their groups) and public (legislative, executive and judicial) bodies.

On the other hand, legal life of society is a subjective process of dialectical transformation of legal reality (legal order) into legal possibility (positive law), and legal possibility (positive law) into legal reality (legal order). In other words, legal life of society is a subjective process of dialectically mutual transformation of legal reality (legal order) and legal possibility (positive law), because motive force of such processes are the subjective wills of participants of legal relations in kind of private persons (individuals and their groups) and public (legislative, executive and judicial) bodies. 'Having translation' into philosophical language, dialectically mutual transformation of legal reality and legal possibility (positive law) represents the mutual transformation of 'phenomenological realism' (legal order) and 'phenomenological idealism' (positive law).

In summary, legal order is accumulated energy that has tendency to be transformed into content of positive law by the legislator. In positive law is accumulated energy that has tendency to be transformed into content of legal order by the private persons and public bodies.

However, will or not will mutually transformed both energies, generally depends on economic, social, political and cultural i.e. meta-legal factors. But priority should be given to legal order than to positive law, because stable and effective legal system could be guaranteed in situation when legislator adequately transformed above mentioned factors, of course, taking into account the standards of Human Rights.

So, I think that each legal system is a result of dialectical interaction of legal order and positive law. So, dialectical Jurisprudence studies the modern problems of legal theory, philosophy and sociology of law at the level of junction of positive law and legal order related to their mutual transformation, spirally and evolutionary development based on the comparison of positive laws and legal orders inside and outside of nation-states. Moreover, Dialectical Jurisprudence focuses on entirely evaluation and prescription of legal system but not on description, analysis and explanation of established legal system. However, for the purpose to achieve stable and democratic legal system jurisprudence must compare legal order and positive law, and creates the model of their harmonization i.e. model of their mutual transformation, spirally and evolutionary development of legal system in whole. In other words, I am putting forward 
unparalleled comparative legal theory, which proposes synergetic model that can help to resolve the traditional problem of confrontation between "sein" ("to be") and "sollen" ("ought to be") through the substan-tiation of relative equality of positive law and legal order, and then through the production of practical mechanism of their mutual transformation, spiral and evolutionary development as the guarantee of conflicts prevention and peacefully resolution at all levels.

Dialectical Interaction between Single Positive Law and Plural Legal Order means the harmonization, mutual transition, spiral and evolutionary development of positive law and legal order, which is also expressed inside and outside the legal system in relation to legal environment, towards the optimization of the any legal system. Such system is under permanent self-organization, self-reproduction and self-catalysis, and is receiving feedback and exchanging legal information with its environment it may move and develop toward decreasing entropy.

Legal order except realization of pure legal constructions i.e. norms of positive law contains also withstand moral principles, norms of traditions, norm of custom, norm of commodity exchange, management norm, local norms, norms of religion, domestic norms, norms of ritual, norms of everyday life etc. etc. All these norms are not isolated from each other, and co-operate with each other, as a result there is setting a social order in a country that distinguishes from the social order of any other country. But as any country of the world lives in the state-organized society the norms of positive law dominate over other social norms, and accordingly - social order is transforming into legal order (1993). In difference from a positive law, which is pure ought to be, legal order is not pure ought to be, because in its forming and becoming have been participated the real (but not possible) legal subjects as bearers of individual rights and duties along with the real (but not hypothetical) facts.

Briefly: positive law in spiral space of society is timeless (not discrete) and relatively - clean energy, however legal order is spiral space of society is temporal (discrete) and relatively - not clean energy. However, both positive law and legal order are not eternal in society. Eternal is only space in whole.

In this aspect, the theory of Clare W. Graves is applicable in greater part to my position. In obedience to the theory of Graves, development is moving on a double spiral: an external spiral is terms of life, problems into that we run, historical period of time, in that we live, place of our residence, circumstances in that we are in society; internal spiral - it our biological features, neurology, psychology, cognitive processes, i.e. our capabilities of mind, through that we "sift" the outer world. External terms constantly co-operate with internal capabilities, arising up at this cooperation position, setting and determining the level of existence. By the way, since the end of $90^{\text {th }}$, this theory is successfully applicable to exact determination of human motivations, permission of conflicts, effective management and achievement of stability and order. ${ }^{2}$

Proceed from abovementioned, human being is only one creator on the planet who has free will and so whose activities have positive and negative circumstances for Nature: positive - when human being is acting in accordance with the Laws of Nature, and negative - when human being is acting against Laws of Nature.

To counterbalance of negative circumstances, Humankind invents norms of behavior like religion, moral and other social norms. As a result in human relationships is establishing just normative order. For the reservation and protection of established just normative order from negative action against Laws of Nature, Humankind invents norms of positive law. As a result of implementation of norms of positive law in human society has been established just legal order as a legal form of normative order. (Savaneli 1983).

In philosophical aspect, human beings as freely willed biological beings are capable to get out of established naturally and objectively cyclically closed normative order and inversely influence upon the normative order i.e. naturally and objectively established practice of individual activities and mutual interactions of members of human community. In the process of influence upon the normative order i.e. naturally and objectively established practice of individual activities and mutual interactions of members of human community sometimes have been appeared naturally and objectively unresolved contradictions among them. For peacefully resolution of such contradiction Humankind set up artificial and subjective outside regulated and protecting norms, among which the norms of moral, religion and law are leadings.

In distinction of moral and religious norms, norms of positive law are divided into material and procedural norms, and in this aspect they are more perfect and efficiency. In the process of activity of artificial norms of positive law is beginning their interaction with the natural and objective norms of normative order, and as a result the normative order transform into just legal order, then legal order into just positive law.

However, violations of symmetry between legal order and positive law civilization many times have felled down in

\footnotetext{
2 See: Graves, Clare W., Levels of Existence: An Open System Theory of Values, he Journal of Humanistic Psychology, Fall 1970, Vol. 10. No. 2, pp. 131-154. Lee, William R., Cowan, Christopher C., and Todorovic, Natasha (eds.), Graves: Levels of Human Existence. Santa Barbara, CA: ECLET Publishing, 2003. Cowan, Christopher C. and Todorovic, Natasha (eds.), The Never Ending Quest: Dr. Clare W. Graves Explores Human Nature. Santa Barbara, CA: ECLET Publishing, 2005.
} 
disorder. Clear examples are massive and increasingly conquest, aggressive, pitiless, ruthless and massive armed wars that is unknown for the animate world. As a result, it has been established anti-natural and unjust normative order. (Savaneli 2003)

So, substantial legal problems of Humankind are at the junction of Philosophy, Anthropology, Sociology and Jurisprudence.

However, since in accordance with the law of entropy normative disorder takes over normative order, for the purpose of minimization of normative disorder humankind "invent" positive law and its watch dog - the State. After that through the positive law there is establishing legal order, which means that instead of normative order and normative disorder accordingly ultimately have been formed legal order and legal disorder. After that, in accordance with the law of synergy, legal disorder takes over of legal order and then for the purpose of minimization of legal disorder the State is changed the positive law. After that such interminable, never-ceasing and never-ending cycle has been repeated constantly.

But this cyclical movement to this day humanity led to no good.

Therefore, for the purpose of eradication of such nightmare on the planet we have proposed a spirally synergistic model of human development.

As we know the word synergy means common concerted action. H. Haken called synergy scientific field that studies the overall action of the elements of the nonlinear medium, generating new structures, that is, explains how the self-organization is moving.

In a broader sense, the term "synergy" refers to the study of the whole subject area of nonlinear science, not only to organize themselves as to the emergence of order out of chaos, but also to dynamically persistent existence of systems that self-organizing, and then entering into a state of deterministic chaos, and to rise to complex structures in this state. As it turned out, the scheme of self-organization at all phases of the homogeneous systems of different nature are similar, and synergistic research program was provided as "trans-disciplinary"." Once said Haken, "Synergetic is growing everywhere," as soon as science approaches to the study of critical states. Synergetic non-equilibrium thermodynamics (Haken) hyper-cycles and autocatalytic reactions in living matter (Eygen) in organic structures (Maturana and Varela), deterministic chaos (Lorenz), fractals (Mandelbrot), nonlinear dynamics and the theory of catastrophes (Sinai, Arnold, Tom), the phenomena of self-organization in social systems (Luhmann), including in the economy (Weiss, Blazeyo, Bauer), policy and Law (Wilke, Teubner), in the cultural development and the history of mankind (Artigiani and Mannermaa). In this paradigm, so called synergistic paradigms combined and implemented in actual research programs of synergetic, including the use of non-linear mathematical methods, and the total synergistic approach, in its philosophical and methodological terms. This approach reveals its heuristic character.

However, there is much more order in the world than is necessary for human existence. In a universe dominated a permanent order counterbalance temporary disorder. Only man is making a mess in the natural order. This axiom becomes the basis for the introduction of differently-shaped norms of behavior. Unfortunately only mankind performs entropy activity because such activity is one of the aspects of life. We must face the truth! On the other hand, it makes no sense to pull people from other organic world. As with all organic life, the goal of human existence as a whole - is the preservation of the species and no more. Just so happened that the world created favorable conditions for the emergence of highly organized life, it should progressively develop balance using all available to it is energetically possible. Thus, it is possible to state explicitly that "the second law of thermodynamics" only indirectly applicable to the synergistic interaction model of legal order and positive law.

In this respect, our theory is applicable in most of the theory K. Graves. According to the theory K. Graves, development is on the double helix: the outer spiral - it's living conditions, the problems we face, the historical period in which we live, where we live, the circumstances in which we find ourselves in a society; internal spiral - our biological features, neurology, psychology, cognitive processes, i.e., our faculties of the mind, through which we "sift" the outside world. Environmental conditions are constantly interacting with the internal capabilities that occurs when this interaction position, installation and determines the level of existence. By the way, since the late $90 \mathrm{~s}$, this theory has been used successfully for accurate detection of human motivation, conflict resolution, good governance and the achievement of stability and order.

In this respect, I would like to emphasize the following. Origin of public human rights is basically connected with the prevention of violations of Natural Human Rights by the States on the level of positive law. Origin of private human rights is basically connected with the violations of legal obligations by the participants of legal relationships on the level of legal order.

These explanations made by me concerning distinction between positive law and legal order in static. 


\section{Legal order and positive law are synergistically dynamic.}

Synergistically dynamic quality of legal order and positive law is celled in their eternal and continuous contradiction. Aim of Civil Society maximally weakening of such contradiction by means of discovery of third dimension that is not located between legal order and positive, but - above them.

Particularly, in the process of understanding of sense of law, Civil Society by means of the State must constantly produce peaceful model of dialectical mutual transformation of legal order and positive law as guarantee of spiral, evolutional and progressive development of Humanity under the untiring supervision of the Universally Recognized Human Rights.

Theoretically, weakness of declarative ethical norms and call for a "basic change of values" against real politics of permanent members of Security Council of UN decisively claims to transform ethical norms into regulative and protective legal norms based on third generation of Human Rights and formation of new sub-discipline of philosophy.

Practically, formation of world judiciary system in order to protect environment is decisive claim that we have faced today. Appropriately, in epoch of anarchically and chaotically developing of globalization, world legal order immanently claims world positive law; otherwise world legal order without world positive law would look like on human being without right hand.

In the process of formation of world positive law, at beginning is necessary adoption of the World Constitution and creation of the World Constitutional Court. The World Constitution could be regulating activity of the UN member-states and UN itself, of course, in condition of abolition UN Security Council as huge survival of the World War II. The World Constitutional Court could be revise compatibility of constitutions of UN member-states to the World Constitution and established practice of UN member-states constitutional courts to the established practice of World Constitutional Court.

Normatively rhythmical and moderately broadening interactively processes could be mathematically formulated. Mathematically formulated legally rhythmical and moderately broadening of interactive processes are precondition of establishing Rule of Human Rights Law in the World. However, this aim will be attained if chronic lag of science of law will not be overcome on the all-round study of legal reality - legal order.

\section{Which is concretely the dynamic model of mutual transformation of legal order and positive law?}

The dynamic model of mutual transformation of legal order and positive law explains theory of synergetic. A word "synergy" means the "general concerted action". G. Khaken named a synergetic scientific direction which studies the general action of elements of nonlinear environment, originates the new structures, that explains how is created selforganization.

In more wide sense term "synergetic" attribute to the study of all subject domain of nonlinear science: not only to self-organization as to arising of order out of chaos but also to dynamically proof existence of the systems, that selforganization, and to including them in the state of the determined chaos, and to the origin of difficult structures in this state.

As turned out, chart of self-organization on all its phases homogeneous for the systems of different nature, and the synergetic research program appeared «trans-disciplinary». As said once Khaken, a "synergetic grows from" everywhere, as soon as science goes near the study of critical conditions. At the same time, under the name of synergetic paradigm unite realization actually of the research programs of synergetic, including application of nonlinear mathematical methods, and general synergistic approach, in this world view and methodological expression. Such approach finds out the heuristic method.

All indicated descriptions of synergetic are typical for a legal order as synergistically system. However, in addition in a difference from wild-life, humanity not only part of wild-life but also free-willed creature, as a result he simply is not written into the chains of co-operation of energies.

If we see that certain conformity of positive law and legal order is in the phenomena we can with the complete founding suppose that this order will proceed, that allows doing prognoses about the future, on that we can be put, us. If Universe would not be well-organized space, people would not be simply able relatively to put in order the life.

System quality of legal order in general during an evolution gradually changes due to senescent and dying, and borne and grow-younger new norm-transmitters, and as a result there are appeared new legal parameters. In any case, legal order as a self-developing system is characterized that he is opened, and he always interacts with a nearby normative environment, exchanged energy and information.

At the same time, instead of that new normative-hierarchical levels have appeared. Thus, the origin of new normative-hierarchical levels affects subjacent levels, changes normative composition of their elements, changes normative property of elements, and laws of their functioning. If we have, it admits, four tier normative organization of elements, appearance of fifth tier will change quarter and lower levels, and then codes of conduct of others will be accordingly other. Thus there is changed understanding of causality in legal order. Here already not enough causality of 
Marks, because its action remains only in final analysis before that it is mediated by the will of man, changing character of law of causality. Here and there is appeared a probabilistic causality, that having a special purpose causality, and it changes all below located normative elements of legal order. And farther, there is converting of possibility into reality.

All of this process can be described by the words of Hegel: at first - abstract possibility, then - real, and then actual. If to shift Hegel approach on modern presentations into language of theory of relativity, it means the following: events are improbable on some stage of development of the system, and at appearance of new level of organization become more or yet less probable, which change probabilistic measures in this system. And that was less probable at one level of development becomes possible after realized, which is converted into reality on other levels of development.

In the complicated homoeostatic systems, as for example, in a legal order, it appeared imagination that along with external space, there is internal space of the homeostatic system. It is, for example, biological organisms, taken in their functioning; it is social groups, taken in the process of their functioning and reproducing. So there is passing from one type of the normative-hierarchical homeostatic system of legal order to other type of the normative-hierarchical homeostatic system of legal order, when the mutual relations of part and whole is changed, changed causal connections, changed space on the whole or partly, and all categories of legal order find other legal sense. All this process has influenced on the dynamics of positive law, and then on the legal system on the whole.

\section{Legal Order, Legal Disorder, Justice, Human Rights}

"If man today does not find a New Way of thinking, Humanity may well be doomed to extinction." Einstein

Modern thinkers would like to understand the real tendency and strategy of the development of a new paradigm with all its complexity and dynamics. It should be noted that philosophy in global era distinguishes two fundamental tendencies: the so called anthropocentrism and des-anthropocentrism. According to the first tendency anthropocentrism - a man as a rational being is placed in the center of the universe, as a guide for future human activity and can predict the future of mankind. According to the second one - des-anthropocentrism - a man is one of energy forces among others. The second orientation is used to describe behavior of systems of all types.

However, both ignore the third dimension which is located not between them but above them.

The anthropocentrism ignores the fact of diversity of energies in the universe.

Des-anthropocentrism ignores the fact of uncial character of human being on our Planet.

Third dimension exists in kind of spiritual energy inside and outside of human being as part of developing environment that unites all substances in different parallel and vertical order in whole space which moves them in mutually interacted spirally dialectical regime and excludes the processes of spontaneous structure genesis.

About des-anthropocentrism we were talking about in two paragraphs above.

In this paragraph we will talk about anthropocentrism on our Planet in substantial sense, in positive and negative senses.

Third dimension of spiritual energy inside of human being in positive sense is represented by the universally recognized human rights and freedoms before States.

Third dimension of spiritual energy inside of human being in negative sense is represented by the universally recognized duties of State before the Citizens.

In human society substantially is reigning natural legal order in which participants of relations naturally distributed mutual obligations and reflected to them rights among them for the satisfactions of their natural economic, social, cultural, political and civil interests. In other words, behaviors of participants of legal order are under the reign of mutual legal obligations and reflected to them rights. Disorder in natural legal order i.e. violation of mutual natural legal obligations is an exception not a rule. For the prevention of disorder in natural legal order i.e. violation of mutual natural legal obligations and reflected to them rights, Humankind artificially creates State bodies and rules of their behaviors i.e. rule of law in the form of material and procedural legal rules.

Despite of that, historically and in glob it was found out that the States became primary and massive violators of their duties of universally recognized human rights and freedoms. In this sense the State could be understand as negative legal order.

Moreover, in the space of international law has been established comic situation: the fact is that the principles of Human Rights are created by the states as the potential violators of Human Rights in direction of violation of SelfDetermination of non-members of SC of UN. Some States mainly act, not only out of respect of law, but also and very often, primarily in their "best" political interests. Recent actions UK and US are the best examples of such situation, say 
nothing about 50 years occupation Arab territories by Israel, and occupation $20 \%$ of territory of Republic of Georgia and Ukraine by Russia with the help of some recruited internal officials. . . Annual reports of Amnesty International and Human Rights Watch clearly indicate on this comic situation. In Asia and Australia region, where meaningful political organization like Council of Europe, Organization of American States, organization of African Union are failing, and there is a conspicuous lack of corresponding human rights conventions and charters. If a state is not fulfilling responsibilities or is actually violating Human Rights, a curious situation arises as to the standing of the other contracting parties in securing from the detracting the observation of its obligations. In this sense, so called - global administrative law represents global danger for humankind. Global administrative law without global government is nonsense, global government without global parliament and global judiciary is global dictatorship of junta of financial blood-suckers.

We are speaking about anthropological catastrophe, about the event that some State-person is not formed still as a "human being". Some politically prejudiced scientists had an attempt to embellish the facade of humankind society with ideological and religious myths to change the vampire's face at least outwardly. But without substantial results." (Savaneli 1993).

As well as the subject of my work is human order I would like to underline the following. Legal order, using Lock's term, is the 'natural state' that stands in need of correction from outside 'artificial state' such as positive law. This idea in analogous form firstly and very simply has expressed by the famous Lock in his well-known essay "Two Treaties of Government".

As I have many times underlined, contrary to Human Rights, which always universal for all disregards of race and etc., the positive law practically links to statehood at the international, national and/or local levels. Only Human Being is a natural entity, all others in society are man-made creations, including laws, but not Human Rights, because Human Rights Law is identical to Human Being. Only one reality is a Human Being and other creatures of God. The State is not creature of God". (Savaneli 2003).

Human being as the subject of positive law basically has the rights before the State and other subjects of positive law, and on the contrary, the State and other subjects of positive law have the obligations before the human being as the subject of positive law. Human being as the subject of legal order basically has the obligations before the State and other subjects of legal order, and on the contrary, the State and other subjects of legal order have the rights before the human being as the subject of legal order. So, obligations of the State and other subjects of positive law before the subject of positive law are the reflection of rights of human being as the subject of positive law. So, the rights of the State and other subjects of legal order before the human being as the subjects of legal order are the reflection of obligations of human being as the subjects of legal order.

Fundament of each Nation-State is a civil society that represents a system of established practice of social relations among individuals and/or their groups. This system is functioning in legal form i.e. in the form of distribution of mutual obligations and reflected to them rights among individuals and/or their groups. Such fundament has been served by the small group of the people that are united in legislative, executive and judicial bodies i.e. in State. That serve bodies are legally ensured of peace, security, social maintenance and sustainable development of civil society. As result, it is established legal order as summary of individuals and/or their groups and public bodies. Out of legal order located 'pure' positive law by which is indirectly governed activities of individuals and/or their groups and directly - activities of public bodies concerning distribution of mutual obligations and reflected to them rights among them. Legal Order and Positive Law consist of Legal System of Nation-State.

Our legal life is constituted by an intersection of different legal orders i.e. by inter-legality. Inter-legality is the phenomenological counterpart of singularity of positive laws. The legal reality is a peculiar mix with rules of mutual obligations and reflected to them rights and actions that is choice making, discretionary, manipulative, sometimes inconsistent sometimes conflict situations among them. Positive law is substantially vertical or mono-centric legal structure while legal order is substantially horizontal or poly-centric legal structure.

The internal and external cresses may also be defined as a shift in the search for strong legal models in the depths legal order in direction of eradication of rule of state's centralism. Such model principally rationalized the positive laws. These models are manifestly suited to the dynamism and mental activity characteristic of modern World. Progress has even been described as equivalent to adventure. Traditional uni-centric models have moreover to be replaced by polycentric models and this entails a restructuring of the concepts which we have been used to. This raises one further issue: the eradication of marginalization of prominent expert groups, whose presence has proved to be an important cultural asset. Moreover, in my work I am not explicitly oriented on the traditional question of jurisprudence: what law is and how the state practices it, but on this question from the point of view of great Jhering's "Der Kampf um's Recht" (1889).

In salvation of this and other problems above and below made easier my 35 years scientific-pedagogical activity and 10 years practical activity as a city judge in the field of private law and criminal law. Based on the Kelsen-Merkl's 
stepped theory, observation of principles of hierarchy of norms by the public bodies is a decisive factor of 'effectiveness' of the legal system, establishment of justice and order in nation-states and reproduction of humanity in whole.

Therefore, I am suggesting steps theory of dialectics.

Universe is normatively rhythmical and moderately broadening system.

Particularly, Universe is such normatively rhythmical system that envelops cyclical process of deducing of 'ought' from 'is' and 'is' from 'ought'. Particularly, Universe is such moderately broadening system that envelops spiral process of mutual transformation of 'is' and 'ought'. These processes dialectically interacted. Normatively rhythmical and moderately broadening interactively processes could be mathematically formulated.

Human society analogically, but not identically (non-causally), is normatively rhythmical and moderately broadening system. Particularly, human society is such normatively rhythmical system that envelops cyclical process of deducing of 'ought' from 'is' and 'is' from 'ought'. Particularly, human society is such moderately broadening system that envelops spiral process of mutual transformation of 'is' and 'ought'. These processes dialectically interacted. Normatively rhythmical and moderately broadening interactively processes could be mathematically formulated. Mathematically formulated normatively rhythmical and moderately broadening interactively processes are precondition of wisdom, justice and stability.

Legal system analogically, but not identically (non-causally), is normatively rhythmical and moderately broadening system. Particularly, legal system is such normatively rhythmical system that envelops cyclical process of deducing of 'ought' from 'is' and 'is' from 'ought'. Particularly, legal system is such moderately broadening system that envelops spiral process of mutual transformation of 'is' and 'ought'. These processes dialectically interacted. Normatively rhythmical and moderately broadening interactively processes could be mathematically formulated. Mathematically formulated legally rhythmical and moderately legally broadening interactively processes are precondition of Rule of Human Rights Law.

In this respect I would like to define notion of dialectical jurisprudence. Dialectical jurisprudence studies rational interaction of facts and norms (legal facts) inside of legal order, and irrational interaction of facts and norms (legal facts) inside of positive law, and then mutual transformation of facts and norms (legal facts) inside of legal system in whole.

In this sense, 'autonomyzation' of legal order and democratization of societal life is indivisible process. In this sense, legal order in its official and unofficial forms has integrative function through which laws and legal reality are in the process of dialectical adaptation and reconciliation. The process of dialectical adaptation and reconciliation promotes conflicts prevention and resolution, and in whole evolutionary development of civil society. On the other side, reality and being are not a state but the process of perpetual renovation, uninterrupted birth. To use Gabriel Marcel's idiomatique expression: Etre c'est être en route. Though, as is well known, Pascal said, human being is a reed in the Universe but human being is sole thinking reed.

In Hegel's philosophy, in the concept of the Spirit no movement can occur without human self-consciousness; every development is by definition self-generating. This is the demand of concreteness that is essential to Hegel.

Therefore, my position is a broadening variation of me theory of legal order based on the comparison of the legal orders of different countries through the lens of Bill of Human Rights. Concerning Human Rights the name of this theory is: "Anthropology of Legal Order".

Dialectical coexistence, synergetic harmonization, mutual transition, spiral and evolutionary development theory open the general mechanism of evolution from disorder to order, by which is opening the door for "taught humankind to be able to join the supernal order of orders" (Shota Rustaveli XII c.). It pushes Humankind from the closed cyclic position to the spiral-evolutionary stage. Any other fixed view would simply be non-dynamical and non-dialectical. "In the frameworks of legal system single State law and plural legal order are interconnected, that is to say, they react on one another; it is precisely this mutual reaction that constitutes motion. Even in conditions of incapability of positive law to adequately regulate appropriate public or private relations, inside legal order is acting the law of conservation of antientropy energy i.e. self-regulatory mechanisms, which able to correct misbalances. The orderly system again contains disorderly factors, and the development of an orderly system with disorderly factors again leads the system into disorder, thereby a new orderly system is produced. Order conquers disorder, and disorder negates order, thus reaching a new orderly process. So, in legal order we have the dialectical unity and contradiction of orders and disorders, as well as in legal system in whole we have orders and disorders between the positive law and legal order. Entropy "win a victory" over anti-entropy an processes, which cause the necessity of outside encroachment. In such circumstances the state have legal obligation to remove entropy through the passing or correcting of positive law. And this process should be in progress endlessly. This is a peacefully model of sustainable development of nation states and humankind." (Savaneli 1981)

In whole, the theory of Mutual Transition, Spiral, Evolutionary and Endlessly Development of Single Positive Law and Plural Legal Order I set on the plane of concord of theory and practice, cognitive and perceptive, on the one side, 
and pragmatic, on the other, dimensions. Idea of finiteness itself is hackneyed and trite. Therefore, the theory of Mutual Transition, Spiral, Evolutionary and Endlessly Development of Single Positive Law and Plural Legal Order step by step lays off a garment of idealism from legal system in whole.

Therefore, I am putting forward a new legal theory, which proposes model that can help to resolve the traditional problem of confrontation between "sein" ("to be") and "sollen" ("ought to be") through the theoretical substantiation of relative equality of positive law and legal order, and then through the production of practical mechanism of their mutual transformation, spiral and evolutionary development as the guarantee of conflicts prevention and peacefully resolution at all levels.

As well as it has been established serious gap concerning interaction between positive law and legal order, my goal is to fill such gap, and I create scientific model of just mutual transformation, spiral and evolutionary development of positive law and legal order (not social order) through the lens of Universal Human Rights. Moreover, I am not based on the distinction of General and Particular Jurisprudence. I have introduced a new - third, united branch of jurisprudence Dialectical Jurisprudence, which envelops the ideas of Dialectical Idealism and Idealist Dialectics in their interactions, and this new - third, united branch of jurisprudence is situated above them.

Many distinguished scholars such as E. Fromm, A. Bullock, M. Maccoby, K. Lorenz, A. Maslow, A. Grinsberg and some others, have argued that a Human destructiveness is more or less immanent characteristic of every human being. ${ }^{3}$

Humankind just because have stated artificial norms of compulsion for human beings. It has been established natural i.e. objective legal order, and artificial i.e. subjective legal order. In short, Human Being, in different from other biological creatures, has the right to be a special spiritual creature. Violations of symmetry between legal order and positive law civilizations many times have fallen down in anarchy. Unfortunately, that is evident and manifest fact of Humankind's history. Clear examples are massive and increasing concussive, aggressive, pitiless and ruthless armed wars which is unknown for the animate world. In this respect, distinction between notions of 'bad men' and 'good men' is unacceptable because such distinction sharply contradicted to the fundamental principles of Christianity and Jurisprudence. However, my starting position is above mentioned. The task of such position is to discover common and distinctive elements among positive law and the legal order, and then the elaboration of "consensual laws" and ways of rapprochement through "an intercultural approach to law and order" based on the universal human rights. Harmonization, mutual and spiral transformation of single positive law and plural legal order at all levels has a trend to conceive a spirit and sense of law. The aim and goal of such transition is to achieve sustainable development of Humankind". (Savaneli 1992)

In my work I am not explicitly oriented on the traditional question of jurisprudence: what law is and how the state practices it, but preferably on these questions from the point of view of great Jhering's "Der Kampf um's Recht" (1889) in the sense of struggle for human rights.

By the way, Heraclites device was: "Men should fight for their laws as for the walls of their city." Human Being without struggle for human rights is only 'instrumentum vocale'.

On the other side, perfect positive law from the point of view of justice never has been exists. Just because Rustaveli (XII c.) introduced the term "Just Law". He was declared the formula: "Just law makes a dry tree green" which reversely means that "unjust law makes a green tree dry".

Remarkable that more than 50 years before Rustaveli Georgian King David the Builder (XI-XII c.C.) in the seminal work "Canon of Repentance" was described fair and impartial judge's decision-making process in the form of lyrical poetry.
"When on doomsday the Code is opened,
And I shall stand to be condemned,
When the ire of the angels shall be roused,
O judge, pass the just sentence as the Lord.
After the blessed rejoice,
The sinners are cast into the flames,
After will began the triumph of justice,
Then have mercy upon me, o Jesus."

\footnotetext{
3 See: E. Fromm, 1973, The Anatomy of Human Destructiveness, ed. Holt, Rinehart and Winston, New York, pp. 4, 6, 10, 39, 45, 76, 203, 204, 237, 242, 244, 346, 357, 358. A. Bullock, 1962, Hitler: A Study in Tyranny, Harper and Row, New York/Evanston, pp. 14, 23. M. Maccoby, 1972, Emotional Attitudes and Political Choices, J. Politics and Society, Geron-X, Inc., Incorporation, Los Altos, pp. 211, 220, 232. K. Lorenz, 1966, On Aggression, Harcourt, Brace \& World, pp. 52, 70. A. Maslow, 1954, Motivation and Personality, Harper \& Bros, pp. 68-69. A. Grinsberg, 1964, Back to the Wall, J. Times Literary Supplement, VIII, p.6. P. Kurtz, 1962, Kierkegaard, J. Temata, N 3, New York, p.117.
} 
In what certainly is expressed dialectics of mutual transformation of positive law and legal order?

If legislators are convinced, that norms of positive law, that they accept, mechanically will bring in an order in public relations, it quite not means that will be so. Practice testifies to reverse. Legislators do not take into account smooth spiral character of development of human society often.

If a positive law is clean normative "ought to be", legal order is not clean "ought to be" because consists of different by the nature "ought to be", i.e. by different by the nature social norms. In addition, if in a positive law fact (hypothesis) and norm (disposition) are constrained logical (ideally), in the legal order they are constrained practically (really). What be more, if positive law is a peak of ramified spiral of identical by the nature norms (particles) of single positive law, legal order is the horizontally ramified network of different by the nature social norms (particles) of legal order, that "over whirlwind" in the spiral dynamics of legal order on the whole. Every next "stage" of spiral development of positive law and legal order relatively satisfies necessities that were not satisfied or repressed by the previous stage of development of positive law and legal order. At the same time, in a difference from a positive law as personification irregularly of locomotive ideal reality, legal order as continuously locomotive to aging run-time material reality, continuously needs updating of habitat by means of new norms of positive law.

Therefore, Harmonization, Synergetic Transition, Spiral and Evolutionary Development of single positive law and plural legal order and disorder moves in spiral (not circle), which based on the Hegel's law of the negation of the negation. The harmonization, mutual transition, spiral and evolutionary development of single positive law and orders and disorders order, and different orders in orders and disorders, using Bertalanffy phrase, is brought about by either 'natural transformation' or 'dynamic transformation' in the case of the social realm.

However, centuries-old world legal practice testifies that in large majority of cases a positive law not adequately reflects and regulates a legal order. Reason that is the permanent ignoring by the legislator of clean basic norms $(\mathrm{H}$. Kelsen), eternal sense of law (G. Naneishvili) on all levels. (Savaneli 1992).

At the same time, in difference of H. Kelsen and G. Naneishvili, clean basic norms and sense of law I filled by the Universally Recognized Human Rights and Freedoms, that are at the greatest level i.e. on the peak of hierarchy of values of Humanity. For this reason principle Rule of Law I have replaced by the principle Rule of Human Rights and Freedoms. (Savaneli 2003)

Rule of Human Rights and Freedoms as sense of law is the third measuring, comprehension of which Humanity must aim constantly." (Savaneli 1990) Thus, sense of law (in my understanding) is a decision factor and condition of smooth and peaceful transition from one valued level of civilization to other. In fact task and aim of positive law is a reduction of entropy processes in the legal order, in language of thermodynamics is their adequate "cooling-down", weakening in the conditions of the increasing "heating" of legal order, and for an achievement society organized in the state that produces new norms or makes alteration in the existent norms of positive law.

However, gradually entropy processes in the legal order score off again, that causes the necessity of making of new legal norms or making alteration for the existent norms of positive law, and then a cycle must recur helically and dialectically. It is an ideal model for progressively-evolutional developing of Humanity.

At the same time, the Universe, Human Society and Legal System are not only solid, durable, firm, strong, stable. They are normatively rhythmical and moderately broadening interactively processes.

The obvious fact is that 'Rule of Law' no more operates effectively inside nation-states and in interstates relations. Just therefore, as outcome from the above mentioned extreme situation, I am putting forward the idea of necessity to replace 'Rule of Law' by 'Rule of Human Rights Law'.

In this sense, I would like to underline that we the people of the world need in New Human Philosophy of Positive Law and Legal Order under the auspice of Universal Human Rights, which links the East and West, North and South, ethics and religions, public and private life, technologies and environmental protection, and the myriad problems, which have never been exist in the history of mankind in widespread aspect.

I have spent my entire scientific and judicial activities confident that a just ruling over Humankind should be based on the model of mutual transformation, spiral and evolutionary development of single positive law and plural legal order through the lens of universal human rights law, and in this sense it is necessary to introduce a new branch of jurisprudence, which will compare legal orders of different countries parallel with comparison of positive laws of different nation states, then, after the comparison of results - a creation of new positive law, and finally systematization, codification and unification of world law. This process should be continuing endlessly.

Practically self-understanding as result of legal transformation of universality of human being is a unique message from Eastern and then Western Philosophical traditions, which forms just legal root for common humanity. The most important task of philosophy of law is to explore the self-understanding of legal reason and to explore established practice of mutual obligations and reflected to them rights inside the legal order based on experience of common 
humanity, which indicates the way of humanization of interpersonal and transpersonal nature of our being in direction of

\section{Socratic "Know Thyself".}

In this respect, search for new methodology of legal philosophy is very important task to reach the practical understanding and peacefully resolution of the current issues and enrichment of new political paradigms and values in the contemporary world. This self-understanding of legal reason gives the neutral and balance comprehension and explores of non-conceptual epistemology of dialectical jurisprudence and transformation it in economic, social, cultural, civil and political fields. I am talking about the necessity of mutual transformation of natural human being (Sein) into artificial human being (Sollen) through the self-understanding of the normative reason and after that the legal reason under the auspice of Universally Recognized Human Rights and Freedoms.

At the same time, un-copious and untiring human instincts will prevent adequate introduction of foregoing model mighty of this world that is presented in the veiled political and economic norms conflicting with naturally legal development of Humanity. Permanent de facto giving of advantage of supremacy of advantageous such norms above supremacy of norms of natural law and natural human rights - was and there is reason of the different from other animal kingdom infamous planning, initiations and organizations of mass wars.

For weakening and removal of chronic misbalance introduction of the model offered by me is again needed, but already at global level. In this sense creation of Universal Constitution of Human Rights and Freedoms and strict legal mechanism can become precondition of transformation of UN Organization.

Coming from all foregoing and as it applies to the global problems of constantly conflicting Humanity, on an orderpaper set the problem of association and collaboration of scientists of natural, social and humanitarian sciences gets up for making of harmonious model of spiral, evolutional and dialectical mutual transformation of "to be" and "ought to be" through making new legal mechanism of providing and protection of Universally Recognized Human Rights and Freedoms.

Concerning human life against thermodynamics figuratively I would like to underline in short the following: the heat that comes from the human soul, often irreversibly absorbed by the excessive ambitions of representatives of three State powers.

\section{References}

Austin, J., (1968), The Province of Jurisprudence, Determined Lectures, Lecture I, Weidenfeld and Nicolsan eds., p. 184.

Bullock, A., (1962), Hitler: A Study in Tyranny, Harper and Row, New York/Evanston, pp. 14, 23.

Cowan, Christopher C. and Todorovic, Natasha (eds.), The Never Ending Quest: Dr. Clare W. Graves Explores Human Nature. Santa Barbara, CA: ECLET Publishing, 2005.

Fromm, E., (1973), The Anatomy of Human Destructiveness, ed. Holt, Rinehart and Winston, New York, pp. 4, 6, 10, 39, 45, 76, 203, 204, 237, 242, 244, 346, 357, 358.

Graves, Clare W., (1970) Levels of Existence: An Open System Theory of Values, the Journal of Humanistic Psychology, Fall 1970, Vol. 10. No. 2, pp. 131-154.

Grinsberg, A., (1964), Back to the Wall, J. Times Literary Supplement, VIII, p.6.

Kurtz, P., Kierkegaard, J. Temata, N 3, New York, 1962 p.117.

Lee, William R., Cowan Christopher C., and Todorovic Natasha (eds.), (2003) Graves: Levels of Human Existence. Santa Barbara, CA: ECLET Publishing,

Lorenz, K., (1966), On Aggression, Harcourt, Brace \& World, pp. 52, 70.

Maccoby, M., (1972), Emotional Attitudes and Political Choices, J. Politics and Society, Geron-X, Inc., Incorporation, Los Altos, pp. 211, 220, 232.

Maslow, A., (1954), Motivation and Personality, Harper \& Bros, pp. 68-69.

Naneishvili, G., (1929), Validity of Positive Law and Experiment of Well-funding of Normative Facts, ed. Tbilisi State University, Georgia.

Naneishvili, G., (1986), Validity of Positive Law and Experiment of Well-funding of Normative Facts, second edition, Tbilisi State University, in Russian, (Translation into Russian made by A. Khocholava and B. Savaneli).

Savaneli, B., (2003), Human Dimension of State Law, Journal "Man and Constitution", Tbilisi, \# 4, pp. 31-39.

Savaneli, B., (1978), Legal Order as Self-Organized System, Journal "Soviet Law", Tbilisi, \# 4, pp. 23-25. Savaneli, B., (1983), Fight for Conservation of Diversity of Life on the Planet, Journal "Soviet Law", Tbilisi, \# 6, pp. 51-54.

Savaneli, B., (1981), Legal Order and Legal Practice, ed. "Soviet Georgia", Tbilisi, in Russian, p. 22-23.

Savaneli, B., (1990), Comprehension of Sense of Law, Journal "State and Law", Tbilisi, \# 8, pp. 15-24.

Savaneli, B., (1992), Legal Order in Correlation with the Positive Law from the Point of View of Comprehension Sense of Law, Doctoral Dissertation Essays, ed. Tbilisi State University, p. 41, in Georgian and Russian.

Savaneli, B., (1993), Legal Theory, Manual, Tbilisi, p. 205, in Georgian.

Savaneli, B., (2002), Globalization of Human Rights, Legal Pluralism and Comparative Law. Report to the Conference on Epistemology and Methodology of Comparative Lawin the Light of European Integration, Brussels, 24th-26 $6^{\text {th }}$ October 2002, Conference Papers, 


\section{4.}

Savaneli, B., (2003) Jus Cogens Character of International Human Rights Law: Philosophy of Law for the 21st Century, Editor "Meridian", Thilisi, Georgia

Savaneli, B., (2003), Globalization, Legal Pluralism and Human Rights, Journal "Themida", Technical University of Georgia, Tbilisi, \# 2 , pp. $11-16$

Savaneli, B., (2003), Jus Cogens Character of International Human Rights Law, Philosophy and Legal Theory for 21st Century, ed. David Agmashenebeli University of Georgia, Tbilisi, in English, p.p. 22-24. (This work is dedicated to the Memory of Giant of Law and International Law - Hans Kelsen).

Savaneli, B., (1993), Law, Religion, Ecology, Chapter in the Manual General Theory of Law, p. 307, in Georgian.

Savaneli, B., (2008), Normative Dimension of Speech Acts, International Conference Proceedings, ed., Technical University of Georgia, Tbilisi, pp. 218-223 (in English).

Savaneli, B., (2013) World Peace Model towards the Implementation of Plan of Dialectical Transformation of Positive Law and Legal Order as Guaranty of Spiral, Evolutionary and Endlessly Development of Humankind under the Auspice of Universal Human Rights Law through the Introduction of Comparative Legal Order Study, in Mediterranean Journal of Social Sciences, MCSER Publishing, Rome - Italy, volume 4, no 3, September 2013, pages 621-636.

Savaneli, B., (1977), The Problem of Legal Order, Journal "Soviet Law", Tbilisi, \# 2, pp. 40-45. 